\title{
The oxidation of soot particulate in the presence of $\mathrm{NO}_{2}$
}

\author{
J.-O. Müller ${ }^{1}$, B. Frank, R. E. Jentoft ${ }^{2}$, R.Schlögl, D. S. Su${ }^{3, *}$ \\ ${ }^{1}$ Present address: Siemens AG, 80333 Munich, Germany. \\ ${ }^{2}$ Present address: School of Chemical, Biological and Materials Engineering, University of Oklahoma, Norman, OK \\ 73019-1004, USA. \\ ${ }^{3}$ Present address: Shenyang National Laboratory for Materials Science, Institute of Metal Research, Chinese \\ Academy of Sciences, 72 Wenhua Road, Shenyang 110016, China.
}

*Corresponding author: e-mail dangsheng@fhi-berlin.mpg.de, dssu@imr.ac.cn

Received 7 December 2011; Received in revised form 10 February 2012; Accepted 1 March 2012, Online 6 April 2012

\section{Abstract}

The microstructure of soot-like carbons is correlated with their reactivity toward combustion. The focus of this study is on Euro IV heavy duty diesel engine soot. Additionally, two soot samples providing lower and larger particle sizes as their most striking property are taken as references. The effect of $\mathrm{NO}_{2}$ addition to the $\mathrm{O}_{2}$-containing gas feed is investigated. It is found that $\mathrm{NO}_{2}$ accelerates the oxidation of soot in the lowtemperature region $\left(250-400^{\circ} \mathrm{C}\right)$ due to an increased surface functionalization with oxygen groups and a subsequent decomposition thereof. Accordingly, initially highly functionalized soot is less susceptible to this effect. The apparent activation energy of combustion is remarkably lowered in the presence of $\mathrm{NO}_{2}$. It is found that the total reactivity correlates with microstructural features such as surface functionalization, size and curvature of basic structural units, stack height, and particle diameter.
\end{abstract}

Keywords: Carbon; Microstructure; Surface functionalization; Thermogravimetry; Kinetics; Combustion

\section{Introduction}

The global emissions of carbonaceous particulate matter from combustion of fossil fuels and burning of biomass are increasing. These particles, which are nonuniformly but widely distributed throughout the troposphere, have a high impact on the atmosphere due to their reactivity with gases such as $\mathrm{NOx}, \mathrm{SOx}$, or $\mathrm{O}_{3}$. The physical and structural properties of environmentally relevant carbons have recently been investigated in detail [1], [2], [3] and [4]. The reactivity and adsorption properties of different substances toward carbon particles are important in order to monitor their behavior in the atmosphere. Studies resolving the relative role of soot and dust particles in the climate changes are also undertaken [5]. Their impact on the bio-organism or even on human health [6], [7] and [8] is assessed by investigation of carcinogenicity.

The majority of soot and carbon black related studies misses a detailed investigation of the microstructure or general morphology. Many studies ignore the fact that several types of carbon have been used in oxidation, reactivity, or atmospheric studies including flame soot, carbon black, and amorphous carbon. This reflects the common opinion (or assumption) that the structure of the soot particles from various sources or synthesis conditions differs little. Most of the studies assume the soot density to be that of graphite. If, however, the nanostructure of soot and carbon black depends on the origin, the question has to be risen how the physical and chemical properties are affected [3], [9] and [10]. Reviews on soot reactivity studies point out that the origin of investigated samples indeed influences their properties [11] and [12]. The present study considers this important link of micromorphology and electronic structure [13] and [14] as well as surface functionalization to reactivity by investigating real diesel engine soot samples.

In order to introduce exhaust treatment systems it is necessary to give an overview of exhaust composition (Fig. 1). Harmful components are included in the exhaust gas to an amount of up to approx. 0.2 vol.\%. The particulate matter (soot, ash, oil, and fuel) contributes to the exhaust with an amount of $20-200 \mathrm{mg} \mathrm{m}^{-3}$. This is 50 times as much as in the case of the Otto four stroke engine (1-10 $\mathrm{mg} \mathrm{m}^{-3}$ ). 


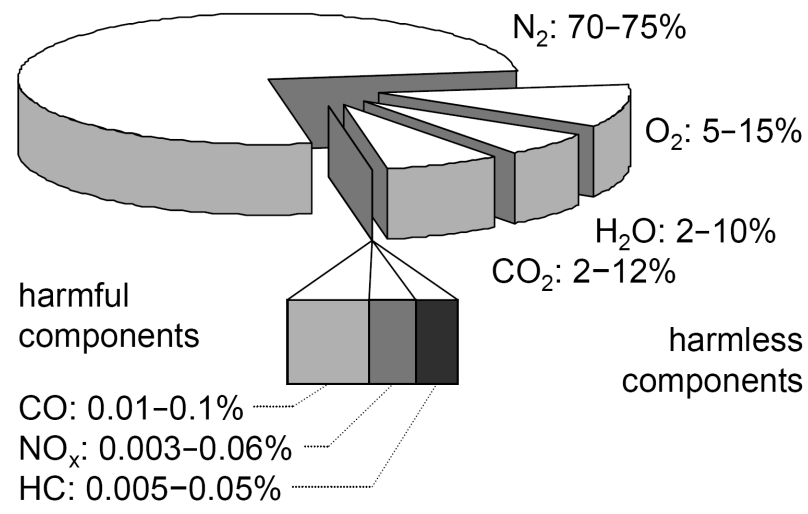

Fig. 1. Composition of heavy duty diesel engine exhaust (data compiled from literature [15]). The diagram shows the amount of basically harmless and harmful compounds in the exhaust gas of a diesel engine.

Practically any particulate matter generated in the diesel engine has to be removed from the exhaust according to the latest EU emission standards [16]. Various attempts have been made to reach the soot particle free diesel engine [12]. Efficient soot oxidation with $\mathrm{O}_{2}$ can be supported by the addition of catalytically active metal oxide nanoparticles [17], [18] and [19] to the fuel. However, this approach involves the risk of potentially even more hazardous emissions. Another possibility is the oxidation of the diesel soot in filters with the catalytic interaction of $\mathrm{NO}_{2}$ (Eqs. (1), (2) and (3)) [12].

$$
\begin{aligned}
& \mathrm{C}(\mathrm{s})+\mathrm{NO}_{2} \rightarrow \mathrm{CO}+\mathrm{NO} \\
& \mathrm{CO}+\mathrm{NO}_{2} \rightarrow \mathrm{CO}_{2}+\mathrm{NO} \\
& \mathrm{NO}+\mathrm{O}_{2} \rightarrow 2 \mathrm{NO}_{2}
\end{aligned}
$$

A wide range of particle trapping and exhaust treatment systems have been introduced and are still under development, for example, ceramic diesel particulate filters, particle traps, and oxidation catalysts with open deposition structures. The general aim is to separate particles in a structure that in principle remains open, and thus does not need to be exchanged. However, care must be taken to ensure that the deposited particles cannot shear off as a result of the aerodynamic forces associated with sudden surges of the gas flow. Removal of particulate matter is done, for instance, by oxidizing the carbon with $\mathrm{NO}_{2}$. For this purpose an oxidation catalyst, in which $\mathrm{NO}_{2}$ is formed, could be placed in front of the filter. At temperatures exceeding $200{ }^{\circ} \mathrm{C}$ this $\mathrm{NO}_{2}$ should continuously remove the deposited soot particles. The present study aims at the general feasibility of this strategy.

Heavy-duty (HD) Euro IV soot, soot produced under black smoke (BS) conditions, and aerosol soot produced by spark discharge are investigated. These materials are chosen in order to demonstrate the variety of pollutant diesel exhaust particles. Moreover, the investigation of bulk and surface properties [1], [2], [3] and [4] are important factors playing a key role in the understanding of the overall behavior of environmentally relevant carbons. The reactivity toward $\mathrm{O}_{2}$ and $\mathrm{NO}_{2}$ is investigated by means of thermogravimetric analysis (TGA).

\section{Experimental}

\subsection{Selection of soot samples}

Euro IV soot is collected from a HD test diesel engine (6.9 1 displacement, $228 \mathrm{~kW}$ ) equipped with a doublestep-controlled supercharging and external-controlled cooled exhaust gas recirculation [20]. The maximal exhaust gas flow at rated speed and full load is $1200 \mathrm{~N} \mathrm{~m}^{3} \mathrm{~h}^{-1}$. This engine is optimized in order to fulfill the Euro IV conditions for HD trucks [16]. The BS soot sample originates from another test diesel engine operating at $30 \%$ load and artificially adjusted for high soot emission by air throttling and reducing rail pressure (blackening number 5). Spark discharge soot (GfG soot) is produced with an aerosol generator (GfG 1000, Palas GmbH, Karlsruhe) [21] operated with two graphite electrodes (CRG München, $200 \mathrm{ppm}$ ash), $150 \mathrm{~Hz}$ discharge frequency, and $4 \mathrm{~L} \mathrm{~min}^{-1}$ argon carrier gas flow.

\subsection{Thermogravimetric analysis of soot oxidati- on}

For TGA, the procedures are as follows: the TG/DSC data is acquired using a Netzsch-STA 449 instrument with $\mathrm{Al}_{2} \mathrm{O}_{3}$ crucibles. The samples are evacuated and the sample chamber is re-filled with $10 \% \mathrm{O}_{2}, 1.5 \% \mathrm{H}_{2} \mathrm{O}$, and balance $\mathrm{N}_{2}$, which is maintained at a total flow rate of $100 \mathrm{~mL} \mathrm{~min}{ }^{-1}$. Steam is added to the feed gas to approach realistic exhaust conditions. The $\mathrm{NO}_{2}$ content is varied between 0 and $1000 \mathrm{ppm}$ and a heating rate of $\beta=5 \mathrm{~K} \mathrm{~min}^{-1}$ is used. The gas phase products are transferred through a heated quartz capillary to a Balzers Thermostar quadrupole mass spectrometer (QMS) operated in SIM mode. The only products observed are $\mathrm{CO}_{2}(\mathrm{~m} / \mathrm{e} \mathrm{44})$ and $\mathrm{H}_{2} \mathrm{O}(\mathrm{m} / \mathrm{e} 18)$. The ion currents for these masses are divided by the ion current for $\mathrm{m} / \mathrm{e} 14\left(\mathrm{~N}_{2}\right)$ to compensate for changes in sensitivity of the QMS. A background is subtracted and the resulting intensity is normalized with regard to the mass of soot. The sample charge used for TGA measurements is about $1 \mathrm{mg}$.

\subsection{Kinetic analysis}

Apparent activation energies $E_{a}$ and frequency factors $\mathrm{A}_{0}$ are calculated from the TGA profiles using the temperature of maximum combustion rate $\mathrm{T}_{\max }$. As shown by Brukh and Mitra [22] (Eq. (4)), the plot of $\ln \left(\mathrm{T}_{\max }^{2} / \beta\right)$ as a 
function of $1 /\left(\mathrm{RT}_{\max }\right)$ results in a straight line with the slope $E_{a}$ and intercept $\ln \left(E_{a} / A_{0}\right)$, from which $E_{a}$ and $A_{0}$ can be determined.

$$
\ln \left(\frac{T_{\max }^{2}}{\beta}\right)=\frac{E_{a}}{R T_{\max }}+\ln \left(\frac{E_{a}}{A_{0}}\right)
$$

It should be stressed that due to the non-isothermicity of the catalyst bed (hot spots) and especially due to the anisotropic structure of (partly) $\mathrm{sp}^{2}$ hybridized carbonaceous materials, which strongly affects the kinetics of combustion [23] on the micro- and macro-kinetic scale (Fig. 3d), this method yields only rough estimates of apparent kinetic constants.

\section{Results and discussion}

\subsection{Structural and electronic characterization}

Representative HRTEM micrographs of the investigated soot samples are shown in Fig. 2. The morphological differences are listed in Table 1. Data from statistical analysis of HRTEM micrographs and quantitative evaluation of EELS spectra [4] indicate that the structure of Euro IV soot is somehow in between BS and GfG soot. BS soot consists of relatively large spheres with rather flat basic structural units (BSUs) in agreement with a high $\mathrm{sp}^{2} / \mathrm{sp}^{3}$ hybridization ratio. Contrarily, GfG soot comprises very small and curved fullerenoid-like subunits with a high degree of $\mathrm{sp}^{3}$ hybridization.

IR adsorption bands according to $\mathrm{C}-\mathrm{O}, \mathrm{C}=\mathrm{O}$, and $\mathrm{O}-\mathrm{H}$ vibrations are identified on each soot sample, however, in highest intensity on the GfG soot, whereas the BS soot provides a comparably low degree of surface functionalization with oxygen groups. The oxygen content in the order GfG > Euro IV > BS is confirmed by XPS analysis. A detailed analysis of investigated soot samples is published elsewhere [4].

\subsection{Oxidation of soot}

Fig. 2a shows the oxidation behavior of Euro IV soot. The influence of the oxidizing agent $\mathrm{NO}_{2}$ is revealed. In the range of $200-500{ }^{\circ} \mathrm{C}$ the mass loss strongly increases in the presence of $\mathrm{NO}_{2}$. The $\mathrm{NO}_{2}$ concentration was varied between 0 and $1000 \mathrm{ppm}$ and a steady increase of reactivity is observed [4]. Beyond $500{ }^{\circ} \mathrm{C}$ the oxidation is not accelerated anymore and the total burn-off temperature of the soot remains unaffected. The remaining weight in the TG experiments (Fig. 2 and Fig. 3 show normalized data) is ash from residual engine lubricant oil. Its amount varies between 0 and $10 \mathrm{wt} . \%$. However, a catalytic impact on soot oxidation can be excluded as repeated TG experiments under identical conditions resulted in good reproducibility of (normalized) weight loss profiles. Fig. 3a reveals differences in
Table 1. Structural and electronic differences of investigated soot samples (data compiled from literature [4]).

\begin{tabular}{cccc}
\hline & Euro IV & BS & GfG \\
\hline $\begin{array}{c}\text { particle } \\
\text { diameter (nm) }\end{array}$ & $18 \pm 6$ & $24 \pm 7$ & $<3$ \\
$\begin{array}{c}\text { BSU size } \\
(\mathrm{nm})\end{array}$ & $1.4 \pm 0.8$ & $1.6 \pm 0.9$ & $1.3 \pm 0.5$ \\
$\begin{array}{c}\text { BSU } \\
\text { curvature } \\
\text { sp }^{2} / \text { sp }^{3} \text { ratio }\end{array}$ & $0.83 \pm 0.06$ & $0.87 \pm 0.04$ & $0.79 \pm 0.08$ \\
$\begin{array}{c}\text { surface } \\
\text { oxygen (at.\%) }\end{array}$ & 12.0 & $76: 24$ & $54: 46$ \\
\hline
\end{tabular}

$\mathrm{CO}_{2}$ evolution during oxidation of Euro IV diesel engine soot. In the absence of $\mathrm{NO}_{2}$, the development of $\mathrm{CO}_{2}$ begins at $300{ }^{\circ} \mathrm{C}$, which is in agreement with the initial mass loss as observed in Fig. 2a. Note that the initial mass loss below $100{ }^{\circ} \mathrm{C}$ is due to desorption of $\mathrm{H}_{2} \mathrm{O}$. The $\mathrm{CO}_{2}$ signal passes a maximum at $580{ }^{\circ} \mathrm{C}$, where the rate of mass loss also reaches its maximum. The profile sharply drops to zero and the soot is completely oxidized at $630{ }^{\circ} \mathrm{C}$. The addition of $\mathrm{NO}_{2}$ notably changes the oxidative behavior of Euro IV soot. A pronounced evolution of $\mathrm{CO}_{2}$ at lower temperatures is observed. The inset in Fig. 3a magnifies the curve shape in the lower temperature range, which is characterized by an onset at $200{ }^{\circ} \mathrm{C}$ followed by a plateau of rather constant rate of $\mathrm{CO}_{2}$ formation rate up to $400{ }^{\circ} \mathrm{C}$. Then, similar to the experiment without $\mathrm{NO}_{2}$, the maximum of $\mathrm{CO}_{2}$ release is at $580{ }^{\circ} \mathrm{C}$ in agreement with the maximum rate of mass loss at this temperature. Finally the soot is burnt at around $610{ }^{\circ} \mathrm{C}$ and the $\mathrm{CO}_{2}$ signal returns to zero.

BS soot apparently contains less volatile compounds than Euro IV soot as indicated by the negligible weight loss in the low temperature region (Fig. 2b). Here, the addition of $\mathrm{NO}_{2}$ does not influence the mass loss profile up to $200{ }^{\circ} \mathrm{C}$. In the temperature range between 250 and $600{ }^{\circ} \mathrm{C}$, an accelerating impact of $\mathrm{NO}_{2}$ on the oxidation rate is revealed. As for Euro IV soot the mass loss over temperature increases with higher $\mathrm{NO}_{2}$ concentration, however, at the heating rate of $2 \mathrm{~K} \mathrm{~min}^{-1}$ the total burn-off temperatures are essentially unaffected at $630 \mathrm{~K}$. Fig. $3 \mathrm{~b}$ shows the m/e 44 traces of the TG experiments with and without the addition of $500 \mathrm{ppm} \mathrm{NO}_{2}$. Differences in $\mathrm{CO}_{2}$ evolution during oxidation of the BS soot are revealed. In the case of the experiment without $\mathrm{NO}_{2}$, the evolution of $\mathrm{CO}_{2}$ begins at $250{ }^{\circ} \mathrm{C}$ as shown in the inset in Fig. 3b. The signal passes a maximum at $645{ }^{\circ} \mathrm{C}$ and reaches zero at $670{ }^{\circ} \mathrm{C}$ indicating that the soot is completely oxidized. In the case of $\mathrm{NO}_{2}$ addition, the MS signal rises at lower temperatures. The formation of $\mathrm{CO}_{2}$ already starts at $150{ }^{\circ} \mathrm{C}$ and at lower temperatures $\left(150-600{ }^{\circ} \mathrm{C}\right)$ the generation of $\mathrm{CO}_{2}$ is higher as compared to the experiment without $\mathrm{NO}_{2}$. However, the signal shows a maximum at a slightly higher temperature of 

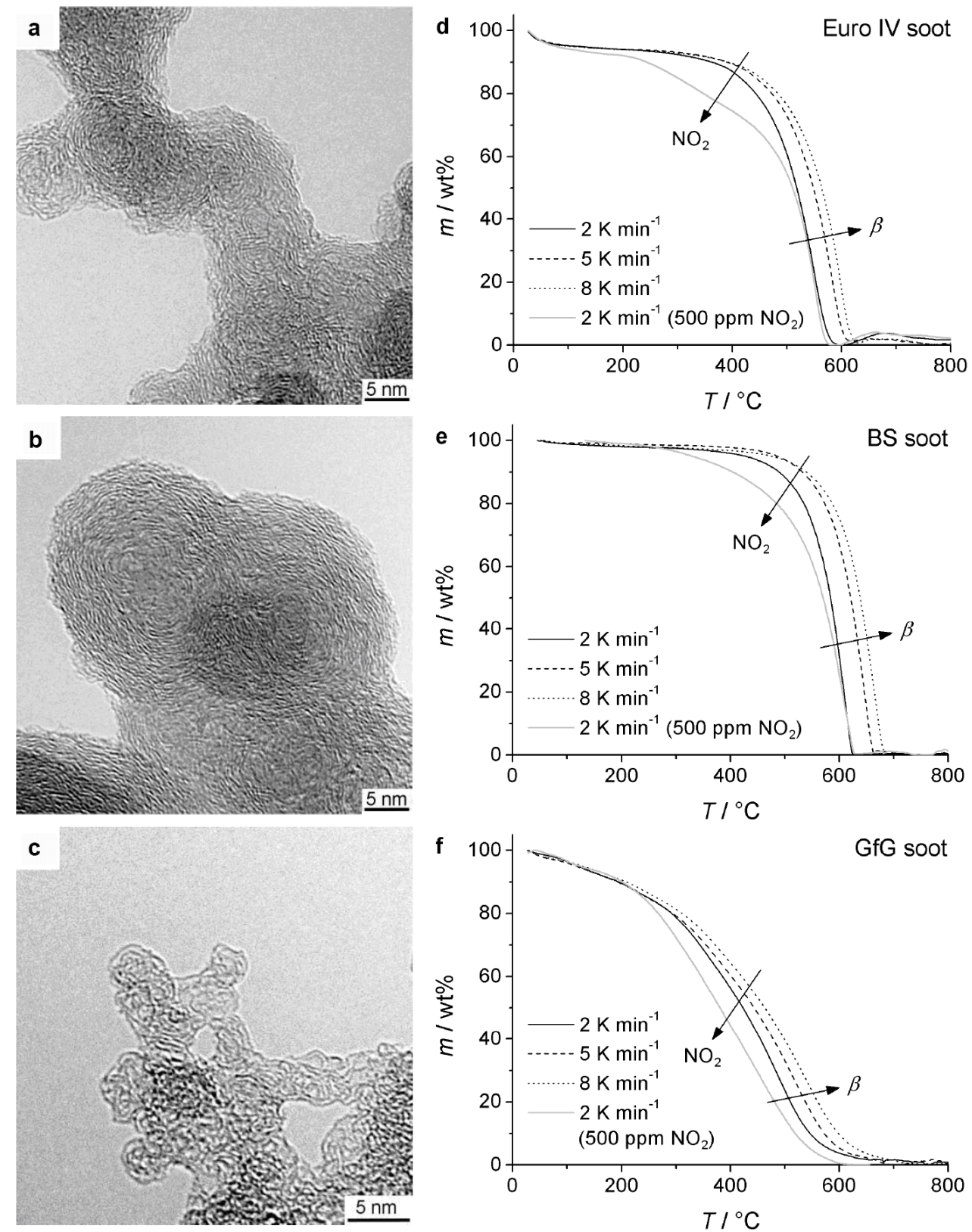

Fig. 2. HRTEM micrographs of (a) Euro IV, (b) BS, and (c) GfG soot. Reprinted from literature [1]. Reproduced by permission of the PCCP Owner Societies. (d-f) TGA measurements of soot samples in $10 \% \mathrm{O}_{2} / 1.5 \% \mathrm{H}_{2} \mathrm{O} /$ bal. $\mathrm{N}_{2}$ and in $500 \mathrm{ppm} \mathrm{NO}_{2} / 10 \% \mathrm{O}_{2} / 1.5 \% \mathrm{H}_{2} \mathrm{O} /$ bal. $\mathrm{N}_{2}$; arrows indicate the effects of $\mathrm{NO}_{2}$ addition and increasing heating rate $\beta$.

$655^{\circ} \mathrm{C}$ and under these conditions the soot is totally burnt at $670{ }^{\circ} \mathrm{C}$

In case of the GfG soot, the $\mathrm{NO}_{2}$ concentration does not significantly influence the mass loss behavior in the temperature range between 50 and $200{ }^{\circ} \mathrm{C}$ (Fig. 2c). Similar to the other soot samples the temperature range between 200 and $590{ }^{\circ} \mathrm{C}$ shows an acceleration of soot oxidation in the presence of $\mathrm{NO}_{2}$. The combustion is completed at $600{ }^{\circ} \mathrm{C}$. The $\mathrm{CO}_{2}$ profiles recorded during the TG experiments reveal only slight differences for the GfG soot (Fig. $3 \mathrm{c})$. The evolution of $\mathrm{CO}_{2}$ begins at $100^{\circ} \mathrm{C}$ and two maxima are observed at 380 and $500{ }^{\circ} \mathrm{C}$, respectively. The sig- nal slowly drops to zero at $750{ }^{\circ} \mathrm{C}$. In the case of $\mathrm{NO}_{2}$ addition, the $\mathrm{CO}_{2}$ signal rises at a lower temperature of around $70{ }^{\circ} \mathrm{C}$. Here, the signal rises faster, showing an increase in the oxidation rate at lower temperatures. The first maximum in $\mathrm{CO}_{2}$ generation is similar in position and intensity with the experiment without $\mathrm{NO}_{2}$, however, the second peak is somewhat less intense and weakly shifted to the higher temperature of $510^{\circ} \mathrm{C}$. Complete oxidation is achieved at $700{ }^{\circ} \mathrm{C}$.

The mechanistic complexity of soot oxidation is reflected in the non-homogeneous curve shapes of TG experiments, especially as observed for the GfG soot sample. The pro 

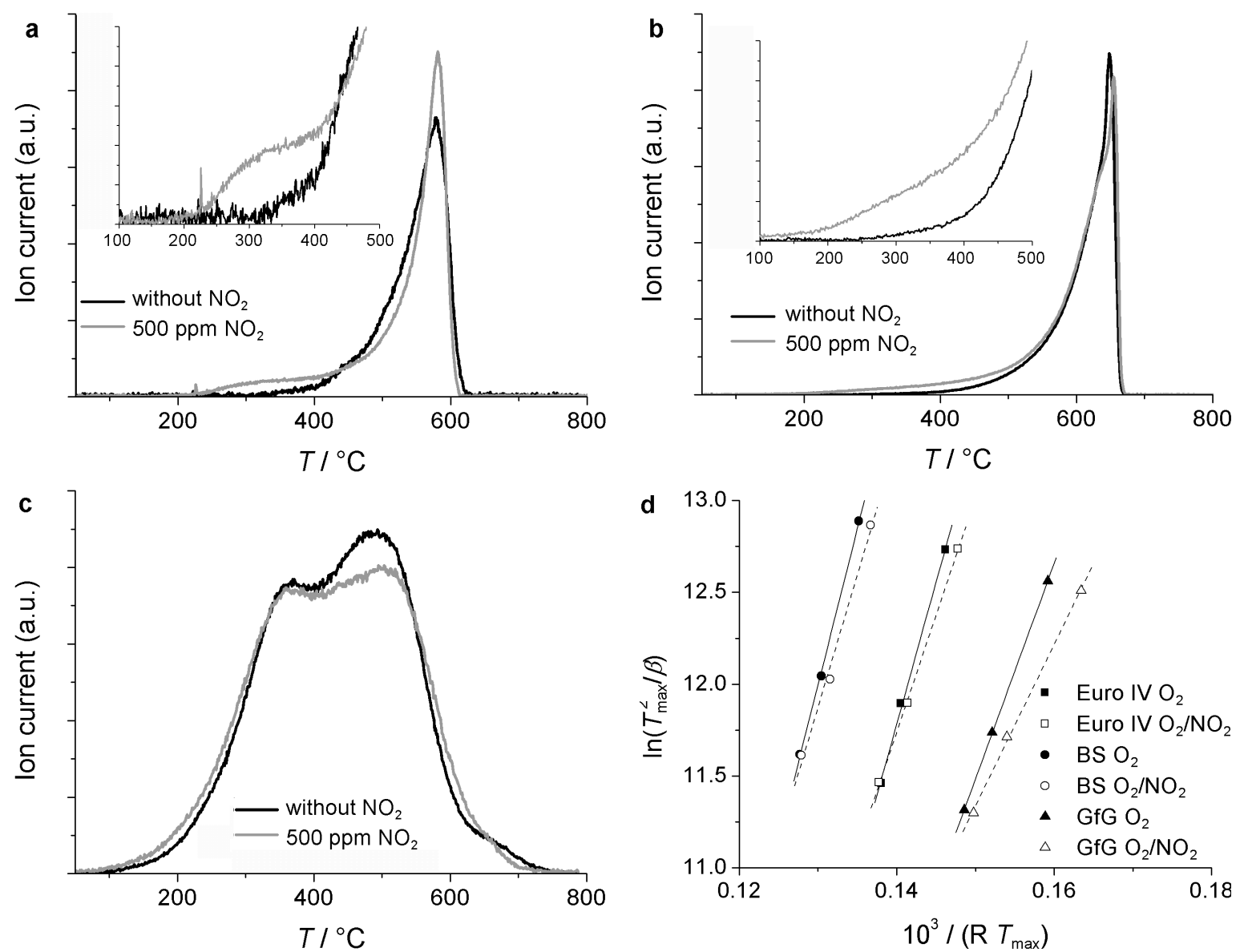

Fig. 3. (a-c) Comparison of $\mathrm{CO}_{2}$ profiles recorded during TGA $\left(5 \% \mathrm{O}_{2} / 1.5 \% \mathrm{H}_{2} \mathrm{O} / \mathrm{bal} . \mathrm{N}_{2}\right)$ in the absence and presence of 500 ppm $\mathrm{NO}$ (inset: magnification of low-temperature $\mathrm{CO}_{2}$ formation); (d) determination of apparent kinetic parameters.

cess is illustrated in Fig. 4 and begins with initial surface oxidation and evaporation of volatile compounds such as adsorbed hydrocarbons and water. The latter process is nicely resolved for Euro IV soot (Fig. 2a). The spherical soot particles are then subjected to pervasive formation of small pores, which increase in size due to enhanced access to gas phase $\mathrm{O}_{2}$ and finally the spheres reduce in size until total combustion. All these processes can contribute to the complex curve shapes as observed in Fig. 2 and Fig. 3.

Apparent activation energies were determined from the change of the temperatures of maximum weight loss when varying the heating rate of TGA (arrows in Fig. 2). As shown in Fig. 3d good linearity is obtained according to Eq. (4). The data are listed in Table 2. It is seen that the apparent activation energies obtained for Euro IV, BS, and GfG soots are lower with $500 \mathrm{ppm} \mathrm{NO}_{2}$. The values drop from 155 to $127 \mathrm{~kJ} \mathrm{~mol}^{-1}$, from 170 to $144 \mathrm{~kJ} \mathrm{~mol}^{-1}$ and from 117 to $88 \mathrm{~kJ} \mathrm{~mol}^{-1}$, respectively.

\section{Discussion}

\subsection{Influence of microstructure on reactivity}

Various models have been developed to describe the structure of soot [25] and [26]. The BSU of soot consists of carbon atoms located at basal plane and edge site positions. Small graphene segments, i.e., BSUs, are frequently aggregated in short stacks with a turbostratic structure. The dimensions of the crystallite stacks considerably vary between different soots and carbon blacks. The relative number and accessibility of potential reactive carbon layer edge sites (aryl $\mathrm{C}-\mathrm{H}$ bonds) depends on the soot nanostructure. These sites are potentially accessible for reaction with $\mathrm{O}_{2}$ or $\mathrm{NO}_{2}$. Theoretical models for carbon gas phase reactions have been developed [27]. Larger graphene layer planes, larger (and hence fewer) crystallites, and concentrically oriented crystallites result in fewer potential reaction sites [28], or sites of lower reactivity. As revealed by the combination of TEM and TG experiments, the fullerenoidic small graphenes are more easily oxidized than the 


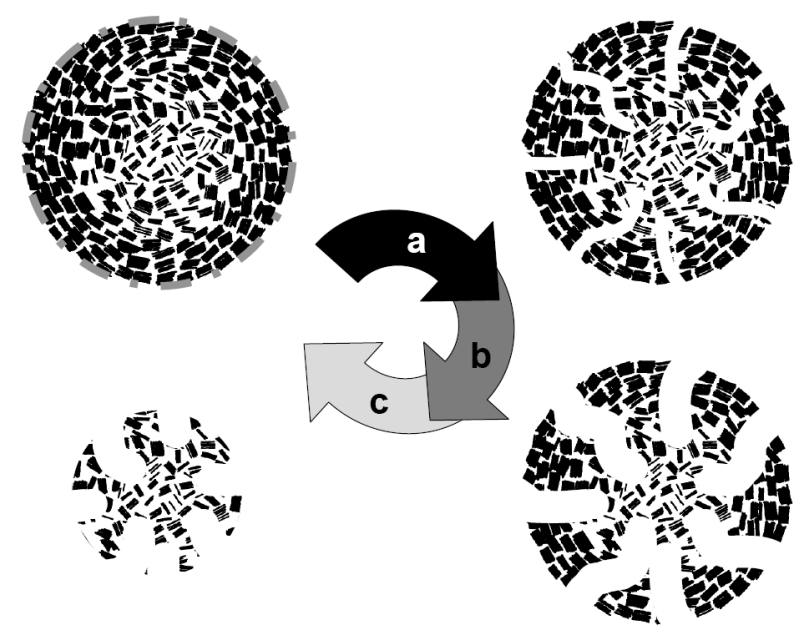

Fig. 4. Illustration of the oxidation of soot spheres: initial surface oxidation and removal of volatile parts is followed by (a) formation of small pores by anisotropic oxidation of graphene layers, (b) pore widening, and (c) size reduction. Carbon sphere reprinted from literature [25], (C) 1997, with permission from Elsevier.

Table 2. Apparent activation energies $\left(\mathrm{kJ} \mathrm{mol}^{-1}\right)$ of soot samples determined from Fig. $3 \mathrm{~d}$ in the absence and presence of $\mathrm{NO}_{2}$.

\begin{tabular}{llll}
\hline & Euro IV & BS & GfG \\
\hline without $\mathrm{NO}_{2}$ & $155 \pm 6$ & $170 \pm 6$ & $117 \pm 1$ \\
$500 \mathrm{ppm} \mathrm{NO}_{2}$ & $127 \pm 3$ & $144 \pm 14$ & $88 \pm 3$ \\
\hline
\end{tabular}

stacked flat graphenes. Thus, the number of such potential sites is a direct reflection of the detailed soot particle nanostructure. Graphite oxidation proceeds anisotropically, i.e., the reactivity of basal plane carbon atoms is far lower than that of edge site carbon atoms [29]. Thus the oxidation rates of graphitized carbon blacks exhibit higher threshold temperatures and much slower rates than the nongraphitized GfG and Euro IV HD diesel engine soots.

Geometrically, carbon atoms in edge sites can form bonds with chemisorbed oxygen due to the availability of unpaired $\mathrm{sp}^{2}$ electrons. Carbon atoms in basal planes can only share one of four electrons for chemical bonds to heteroatoms. Consequently, the observed reactivity will be an average of basal vs. edge site carbon atom reactivities for graphitic layer planes of finite dimensions [30]. As the layer plane size decreases, the number of edge site carbon atoms will necessarily increase in proportion to the number of basal plane carbon atoms, allowing one to expect the overall reactivity to increase. In addition to the size of the graphene segments, their relative curvature will also influence their oxidation rate. Curvature arises from non-6membered carbon rings within the aromatic framework. This curvature imposes bond strain as the orbitals overlap, and the electronic resonance stabilization is lessened [31]. Therein the $\mathrm{C} \_\mathrm{C}$ bonds are weakened and individual atoms are more exposed, i.e., they are more susceptible to oxidative attack [32]. This leads to the observed structure reactivity correlation. It is for these same reasons that fullerenes and carbon nanotubes are less resistant toward oxidation than planar graphite [23]. The GfG soot is the most reactive of all three investigated materials. The reason is the highly defective structure, which is observed in the TEM micrographs. The material consists of fine subunits not larger than $3 \mathrm{~nm}$ building up agglomerates. Strongly bent graphenes lead to localized double bonds resulting in an olefinic structure [33]. Theoretical investigations of nanocarbons predict the influence of geometric changes on chemical properties (increasing reactivity upon increasing curvature) [34]. TEM and TPO results are in perfect agreement, as evidenced by the low apparent activation energy of $117 \mathrm{~kJ} \mathrm{~mol}^{-1}$ that is needed to oxidize GfG soot.

The Euro IV HD diesel engine soot is less reactive than the GfG soot but still more than the BS soot. The analysis of the apparent activation energy that is necessary to oxidize the Euro IV soot results in an intermediate value of $155 \mathrm{~kJ} \mathrm{~mol}^{-1}$. One reason is seen in the size distribution of primary particles - the majority of the particles have a size of 10-15 nm. Comparing the TEM images the Euro IV soot appears more compact and thus is less accessible to oxygen than the GfG soot. However, the crucial reason is seen in the multi-shell fullerenoid-like structure with a defective surface. The defective non-six-membered carbon rings may produce highly localized olefinic electronic structures prone to the addition of molecular oxidants [35], as already described for the GfG soot. Not only the morphology but also the surface chemistry of the Euro IV soot differs from that of the GfG soot.

The BS soot is less prone to oxidation due to the well developed graphitic properties. The BSUs are flat, indicating a less defective structure. One observes domains where graphenes are stacked forming graphitic nanocrystallites. The ratio of edge to in-plane carbon atoms is low. These structures decrease the reactivity [11] and [36]. Additionally the local density is higher. The higher apparent activation energy of $170 \mathrm{~kJ} \mathrm{~mol}^{-1}$ as obtained from the TG measurements is a clear indication for these influences [37]. A lower amount of defects should result in fewer functional groups and this is reflected in the DRIFT spectra [4]. The high rate of oxidation of the GfG and the Euro IV soot is due to the defective graphenes that are more reactive than these of the BS soot.

\subsection{Influence of gas phase on reactivity}

The influence of $\mathrm{NO}_{2}$ and $\mathrm{H}_{2} \mathrm{O}$ on diesel engine soot oxidation has been investigated in various studies prior to this work. The oxidation of the carbon black Printex-U, graphite and activated carbons in presence of $\mathrm{NO}_{2}, \mathrm{O}_{2}$, and $\mathrm{NO}$ on soot aerosols as well as on diesel engine soot have 
been investigated [38], [39] and [40]. Phenomenological models for soot oxidation were presented [37], [41] and [42]. Other groups investigated the influence of $\mathrm{O}_{2}$ and $\mathrm{NO}_{2}$ on the generation of surface oxygen groups [43] and [44]. The influence of an optimized design of particulate traps on the soot oxidation was tested [45], as well as the influence of engine settings and exhaust gas temperatures [46].

It is generally accepted, that $\mathrm{NO}_{2}$ enhances the oxidation of soot and carbon black. The effect of induced reactivity with higher amount of $\mathrm{NO}_{2}$ is an effect of enhanced graphene functionalization with oxygen groups via the following reactions (Eqs. (5) and (6)) [43],

$$
\begin{aligned}
& \mathrm{CC}_{\mathrm{f}}+\mathrm{NO}_{2} \rightarrow \mathrm{CC}_{\mathrm{f}}(\mathrm{O})+\mathrm{NO} \\
& \mathrm{CC}_{\mathrm{f}}(\mathrm{O})+\mathrm{NO}_{2} \rightarrow \mathrm{C}(\mathrm{O}) \mathrm{C}_{\mathrm{f}}(\mathrm{O})+\mathrm{NO}
\end{aligned}
$$

where $\mathrm{CC}_{\mathrm{f}}$ indicates a free edge carbon atom, $\mathrm{CC}_{\mathrm{f}}(\mathrm{O})$ and $\mathrm{C}(\mathrm{O}) \mathrm{C}_{\mathrm{f}}(\mathrm{O})$ both represent surface oxidized carbon atoms, which can decompose yielding $\mathrm{CO}$ or $\mathrm{CO}_{2}$. This effect takes place due to the easier dissociation of $\mathrm{NO}_{2}$ on graphenes in comparison with the $\mathrm{O}_{2}$. It has been shown in a recent ab initio modeling study of the oxidation of the basal plane of graphene that the initial step is chemisorption of an oxygen atom across a $\mathrm{C} \_\mathrm{C}$ bond of the graphene sheets. The calculated binding energy of the chemisorbed oxygen atom is $250-300 \mathrm{~kJ} \mathrm{~mol}^{-1}$, which must be compared with the bond dissociation enthalpies $\mathrm{E}_{\mathrm{d}}\left(\mathrm{O} \mathrm{O}_{-} \mathrm{O}\right)=498$ and $\mathrm{E}_{\mathrm{d}}\left(\mathrm{ON} \_\mathrm{O}\right)=306 \mathrm{~kJ} \mathrm{~mol}^{-1}$, respectively. The reaction is exothermic, but enhanced with $\mathrm{NO}_{2}$ due to the lower dissociation energy. Transferred to the results of soot and carbon black oxidation, this means that at lower temperatures the first step to the oxidation of the carbons, being the functionalization, is enhanced. The total oxidation of the carbon to $\mathrm{CO}_{2}$ occurs at lower temperatures. When comparing the oxidation in various amounts of $\mathrm{NO}_{2}$, it is apparent that highly functionalized carbons are less prone to an enhancement of oxidation with $\mathrm{NO}_{2}$. The GfG soot does not display such significant differences in the oxidation curves as the Euro IV or the BS soot. From the TG experiments it is apparent that the influence of the oxidation of the soot through $\mathrm{NO}_{2}$ is dominant at temperatures in the range of $200-450{ }^{\circ} \mathrm{C}$. The first step of creating an oxygen functional group is easier due to the strong oxidative properties of the $\mathrm{NO}_{2}$. The addition of $\mathrm{NO}_{2}$ increases the oxidation of the graphitic parts of the soot. Apparently the oxidation of

\section{References}

[1] J.-O. Müller, D.S. Su, U. Wild, R. Schlögl, Phys. Chem. Chem. Phys., 9 (2007), pp. 4018-4025

[2] J.-O. Müller, D.S. Su, R.E. Jentoft, U. Wild, R. Schlögl, Environ. Sci. Technol., 40 (2006), pp. 1231-1236

[3] D.S. Su, J.-O. Müller, R.E. Jentoft, D. Rothe, E. Jacob, R. Schlögl, Top. Catal., 30-31 (2004), pp. 241-245

[4] J.-O. Müller, Investigations on Environmental Carbons, Technische Universität Berlin (2005) graphitic materials only in the presence of $\mathrm{O}_{2}$ does not take place at temperatures below $400{ }^{\circ} \mathrm{C} . \mathrm{NO}_{2}$ lowers the apparent activation energy at temperatures relevant for diesel soot oxidation. For temperatures between 50 and $350{ }^{\circ} \mathrm{C}$, activation energies in the range of $50-80 \mathrm{~kJ} \mathrm{~mol}^{-1}$ are reported. This correlates at least qualitatively with the data obtained in this study (Table 2). Nevertheless, the general soot nanostructure plays an important role in the overall reactivity. Different reaction rates and activation energies are reported in the literature. In many cases this is attributed to different experimental setups. In this work it is obvious, that the differences in activation energies and rates stem from the differences in microstructure of the soot. So even in the case of gasification of soot with $\mathrm{NO}_{2}$, the structure reactivity correlation previously discussed holds. It is important to mention that in the case of the GfG soot the overall reaction is enhanced but not as significantly as in the case of the Euro IV or the BS soot. It seems that the more functionalized the graphenes are, the less the soot oxidation can be enhanced by $\mathrm{NO}_{2}$. Probably, $\mathrm{NO}_{2}$ generates thermodynamically favored surface functional groups that play the key role in carbon oxidation at temperatures below $400{ }^{\circ} \mathrm{C}$.

\section{Conclusion}

The widely accepted structure-reactivity-correlation for the oxidation of nanostructured carbonaceous materials could be confirmed for three structurally differing soot samples. The $\mathrm{NO}_{2}$ rich atmosphere enhances the soot oxidation at lower temperatures by generation of active surface functional groups. The enhanced reactivity of soot emitted from modern diesel engines plays an important role in the exhaust aftertreatment. With both of these issues the diesel engine exhaust aftertreatment is feasible at temperatures typical of the exhaust train.

\section{Acknowledgements}

This work was part of the project "Katalytisches System zur filterlosen kontinuierlichen Rußpartikelverminderung für Fahrzeugdieselmotoren" supported by the Bavarian Research Foundation. The authors thank Klaus Friedel for helpful discussion.
[5] J.E. Hansen, A.A. Lacis, Nature, 346 (1990), pp. 713-719

[6] S. Fiorito, A. Mastrofrancesco, G. Cardinali, E. Rosato, F. Salsano, D.S. Su, A. Serafino, M. Picardo, Carbon, 49 (2011), pp. 5038-5048

[7] D.S. Su, A. Serafino, J.-O. Müller, R.E. Jentoft, R. Schlögl, S. Fiorito, Environ. Sci. Technol., 42 (2008), pp. 1761-1765 
[8] T. Thurnherr, D.S. Su, L. Diener, G. Weinberg, P. Manser, N. Pfänder, R. Arrigo, M.E. Schuster, P. Wick, H.F. Krug, Nanotoxicology, 3 (2009), pp. 319-338

[9] D. Su, R. Jentoft, J.-O. Müller, D. Rothe, E. Jacob, C. Simpson, Ž. Tomović, K. Müllen, A. Messerer, U. Pöschl, R. Niessner, R. Schlögl, Catal. Today, 90 (2004), pp. 127-132

[10] J.-O. Müller, D.S. Su, R.E. Jentoft, J. Kröhnert, F.C. Jentoft, R. Schlögl, Catal. Today, 102-103 (2005), pp. 259-265

[11] R.L. Vander Wal, A.J. Tomasek, Combust. Flame, 136 (2004), pp. 129-140

[12] B.A.A.L. van Setten, M. Makkee, J.A. Moulijn, Catal. Rev.: Sci. Eng., 43 (2001), pp. 489-564

[13] M.E. Schuster, M. Hävecker, R. Arrigo, R. Blume, M. Knauer, N.P. Ivleva, D.S. Su, R. Niessner, R. Schlögl, J. Phys. Chem. A, 115 (2011), pp. 2568-2580

[14] M. Knauer, M.E. Schuster, D.S. Su, R. Schlögl, R. Niessner, N.P. Ivleva, J. Phys. Chem. A, 113 (2009), pp. 13871-13880

[15] J.P.A. Neeft, M. Makkee, J.A. Moulijn, Fuel Process. Technol., 47 (1996), pp. 1-69

[16] http://www.dieselnet.com/standards/eu/, 2011.

[17] P. Ciambelli, P. Corbo, M. Gambino, V. Palma, S. Vaccaro, Catal. Today, 27 (1996), pp. 99-106

[18] G. Mul, F. Kapteijn, J.A. Moulijn, Appl. Catal. B, 12 (1997), pp. $33-47$

[19] A. Setiabudi, J. Chen, G. Mul, M. Makkee, J.A. Moulijn, Appl. Catal. B, 51 (2004), pp. 9-19

[20] E. Jacob, D. Rothe, R. Schlögl, D.S. Su, J.-O. Müller, R. Niessner, C. Adelhelm, A. Messerer, U. Pöschl, K. Müllen, C. Simpson, Z. Tomovic, H.P. Lenz (Ed.), Internationales Wiener Motorensymposium, vol. 24, VDI-Verlag (2003), pp. 19-45

[21] C. Helsper, W. Mölter, F. Löffler, C. Wadenpohl, S. Kaufmann, G. Wenninger, Atm. Environ., 27 (1993), pp. 12711275

[22] R. Brukh, S. Mitra, J. Mater. Chem., 17 (2007), pp. 619-623

[23] B. Frank, A. Rinaldi, R. Blume, R. Schlögl, D.S. Su, Chem. Mater., 22 (2010), pp. 4462-4470

[24] T. Ishiguro, Y. Takatori, K. Akihama, Combust. Flame, 108 (1997), pp. 231-234

[25] C.M. Sorensen, G.D. Feke, Aerosol Sci. Technol., 25 (1996), pp. $328-337$

[26] Z.A. Mansurov, Combust. Explos. Shock Wave, 41 (2005), pp. $727-744$
[27] Z. Zhu, G.Q. (Max) Lu, J. Finnerty, R.T. Yang, Carbon, 41 (2003), pp. 635-658

[28] C. Li, T.C. Brown, Carbon, 39 (2001), pp. 725-732

[29] R. Schlögl, Chem. unserer Zeit, 28 (1994), pp. 166-179

[30] K. Zaghib, X. Song, K. Kinoshita, Thermochim. Acta, 371 (2001), pp. 57-64

[31] G. Ghigo, A. Maranzana, G. Tonachini, C.M. ZicovichWilson, M. Causà, J. Phys. Chem. B, 108 (2004), pp. 32153223

[32] H. Ulbricht, G. Moos, T. Hertel, Phys. Rev. B, 66 (2002), p. 075404

[33] M.S. Dresselhaus, G. Dresselhaus, P. Eklund Science of Fullerenes and Carbon Nanotubes Academic Press, San Diego (1996)

[34] K. Choho, W. Langenaeker, G. Van De Woude, P. Geerlings, J. Mol. Struct. (Theochem), 338 (1995), pp. 293-301

[35] J. Poater, X. Fradera, M. Duran, M. Solà, Chem. Eur. J., 9 (2003), pp. 1113-1122

[36] R.L. Vander Wal, A.J. Tomasek, Combust. Flame, 134 (2003), pp. 1-9

[37] J.P.A. Neeft, T.X. Nijhuis, E. Smakman, M. Makkee, J.A. Moulijn, Fuel, 76 (1997), pp. 1129-1136

[38] K.-Y. Choi, N.W. Cant, D.L. Trimm, J. Chem. Technol. Biotechnol., 71 (1998), pp. 57-60

[39] S. Kamm, H. Saathoff, K.-H. Naumann, O. Möhler, U. Schurath, Combust. Flame, 138 (2004), pp. 353-361

[40] F. Arens, L. Gutzwiller, U. Baltensperger, H.W. Gäggeler, M. Ammann, Environ. Sci. Technol., 35 (2001), pp. 21912199

[41] F. Jacquot, V. Logie, J. Brilhac, P. Gilot, Carbon, 40 (2002), pp. 335-343

[42] B.A. Lur'e, A.V. Mikhno, Kinet. Catal., 38 (1997), pp. 490 497

[43] A. Setiabudi, M. Makkee, J.A. Moulijn, Appl. Catal. B, 50 (2004), pp. 185-194

[44] J. Zawadzki, M. Wiśniewski, K. Skowrońska, Carbon, 41 (2003), pp. 235-246

[45] A. Setiabudi, M. Makkee, J.A. Moulijn, Appl. Catal. B, 42 (2003), pp. 35-45

[46] I.P. Kandylas, G.C. Koltsakis, Ind. Eng. Chem. Res., 41 (2002), pp. 2115-2123 